\title{
A Review on Muffler Design for Exhaust Noise Attenuation
}

\author{
Prasad V.Shinde $^{1}$, P.M.Gavali ${ }^{2}$, R.A.Barawade ${ }^{3}$, Y.B.Mohite ${ }^{4}$, P.B.Shinde ${ }^{5}$ \\ ${ }^{1,2,3,4}$ Assistant Professor, Automobile Engg. Dept, Annasaheb Dange College of Engineering, \\ Ashta, Maharashtra, India \\ ${ }^{5}$ Assistant Professor, Electronics \& Telecommunication Dept., \\ Padmabhooshan Vasantraodada Patil Institute of Technology, Budhgaon, Maharashtra, India \\ 1prasadshinde7174@gmail.com, 2pmgavali89@gmail.com \\ 3rohit9301@rediffmail.com, ${ }^{4}$ yogesh.yp999@gmail.com, ${ }^{5}$ pbshinde305@gmail.com
}

\begin{abstract}
The pressure waves escape from the engine exhaust with a high velocity producing an offensive exhaust noise. A properly designed exhaust silencer is helpful to reduce exhaust noise. In these review paper different types of mufflers and a performance characteristic of muffler have been studied. In designing, different parameter which has been to taken into the consideration. These parameters affect the muffler efficiency. This paper also focuses on sound attenuation, back pressure which is most important criteria for selection of muffler.
\end{abstract}

Keyword- Muffler, Noise, Diesel Engine, Transmission Loss, Insertion Loss

\section{INTRODUCTION}

Noise is an annoyance for present days. The internal combustion engine is a main contributor in increasing unwanted sound level. There may be permanent hearing loss when a person is exposed to noise above a certain level. Vibrations of the exhaust gases is dampened by the muffler to reduce the amount of sound generated by the engine muffler is designed by considering as an acoustic soundproofing device to reduce loudness of sound pressure created by engine.

In petrol and diesel engines during exhaust process it set up pressurized pulsating flow. As the engine speed and load increases pressure level varies. At higher speeds and loads, the exhaust manifold pressure is above atmospheric pressure. These pressure waves travel at speed of the sound relative to the exhaust gas. These pressure waves escape with a high velocity producing an offensive exhaust noise. A properly designed exhaust silencer is helpful to reduce exhaust noise. Exhaust gas propagating through small pipes, produces some resonance in such frequency range that causes audible sound.

\section{NOISE STANDARD IN INDIA}

The central pollution control board constituted committee on noise pollution control. The committee recommended noise standards for ambient air and for automobiles according to various zones are as follows:-

\begin{tabular}{|c|c|c|}
\hline Area & Day time noise limit (dB) & Night time noise limit (dB) \\
\hline Industrial area & 75 & 70 \\
\hline Commercial area & 65 & 55 \\
\hline Residential area & 55 & 45 \\
\hline Silence zone & 50 & 40 \\
\hline
\end{tabular}

The Noise Limits for vehicles were notified by Environment (Protection) Amendment Rules, 2000. Noise limits for vehicles applicable at manufacturing stage applicable from 1st April, 2005 are as given in the table below:

\begin{tabular}{|c|c|}
\hline Categories & Noise limit in dB \\
\hline Motor cycle and scooter & 75 to 80 \\
\hline Three Wheelers & 77 to 80 \\
\hline Passenger cars & 78 to 80 \\
\hline Transport Vehicles & 77 to 80 \\
\hline
\end{tabular}




\section{MUFFLER SELECTION}

In order to select suitable type of muffler, some basic information is required regarding how muffler works. Attenuation of sound is done by two methods reactive attenuation and absorptive attenuation. In reactive attenuation sound waves reflects back towards noise source. In absorptive attenuation, sound energy is absorb by sound absorbing material converting it into small amount of heat. Sometimes, combined mufflers (both reactive and absorptive muffler) are used in industrial application.

Following are some considerations while selecting a muffler

- Diameter of inlet of muffler and outlet of muffler.

- Number inlet and outlets

- Size and weight constraints

- Material used

\section{- Transmission loss}

\section{DESIGN TARGETS}

Effectiveness of muffler can be quantified by transmission loss. Transmission loss is nothing but sound energy that is prevented from travelling through a muffler.

$\{$ Transmission loss $=$ (sound power level entering $)-($ sound power level exiting the muffler $)\}$

- Insertion loss

The insertion loss is the sound pressure level difference without and with the muffler present. Insertion loss depends not only on the muffler geometry but also on the source impedance and the radiation impedance

- Backpressure

Back pressure caused by the exhaust system muffler of an automotive four-stroke engine has a negative effect on engine efficiency resulting in a decrease of power output that must be compensated by increasing fuel consumption.

- $\quad$ Noise Target

As per the rules and regulations the value of the sound is set at particular level.

\section{DESIGN PARAMETERS}

1. Diameter of the muffler

2. Length of the muffler

3. Number of chambers

4. Number of outlet pipes

5. Internal Configurations

6. Perforation Percentage

- Basic Classification of Muffler:-

\section{TYPES OF MUFFLER}

1. Baffle Muffler- Baffle is nothing but the obstructions placed one after another. When exhaust gases passes from inlet to outlet of muffler it obstruct one after another, so at outlet sound will completely minimized. Any shape of baffles can use in muffler. Generally baffles are in cylindrical in shape. The drawback of this muffler is the low efficiency and loss of engine power.

2. Resonance Muffler- It is also known as Helmholtz type muffler. It consists of many number of ports with resonators. All of this is connected in series with a pipe which flows exhaust gasses. The main advantage of this type of muffler is there is no any obstruction hence there is no resistance to flow, so attenuation can achieve without effect on engine power.

3. Wave cancellation muffler- In such type of active cancellation phenomena is used. It is a small box, in which exhaust gases are divided into different parts, these different parts parts are adjusted in such a way that both are coincide with each other which causes cancellation effect, it reduces noise completely zero level. The only disadvantage is that it has been used only for specific frequencies.

4. Absorptive Muffler- These type of muffler consists of absorptive material which absorbs the sound coming out from exhaust manifolds. This type of muffler is used in racing cars in automobiles.

5. Combination muffler- These type of muffler is the combination of both resonance or reactive muffler and absorber muffler. Resonance type muffler has disadvantage of reduction in power generated by engine and increasing back pressure. The absorber type of muffler has disadvantage of incomplete noise reduction and operating at lower frequencies only. So combined resonance/reactive and absorber type of muffler are 
implemented to give better effects.

- Special Mufflers:-

1. Vector muffler- These muffler used in heavy duty trucks and container. In this muffler, high pressure exhaust gases pulses are cancel each other by using angle muffler.

2. Spiral muffler- These types of mufflers are used in light duty applications such as small cars and trucks. The cost muffler are low as compare to other type of muffler.

3. Aero turbine muffler- Aero turbine muffler uses vacuum, as the same way vector muffler uses angle muffler. This creates vacuum at regular intervals which cause negative backpressure and sound gets minimized.

\section{LITERATURE REVIEW}

Ying-li Shao et al [1] proposed that new concept of exhaust muffler using active cancellation phenomena. Comparison of the existing passive muffler with new muffler in terms of sound pressure level and specific fuel consumption is shown. A new concept of exhaust muffler is proved by the numerical simulation. New muffler shows superior performance for lower backpressure hence lower specific fuel consumption. Chen Liu et al [2] expressed 3D time-domain CFD approach to calculate acoustic attenuation performance of silencer. Cross flow perforated tube silencer and straight-through perforated tube silencer are analyzed using CFD approach and transmission loss of both the muffler has been formulated. Results show a good agreement with experimental results. Jun Chen et al [3] describes physical numerical modeling of the flow field of the muffler. CFD approach is used to simulate the muffler. Distribution and influence of the flow field has been analyzed. S. Biswas [4] examined a combination and reactive muffler for a single cylinder four stroke Diesel engine. Performance of the engine is evaluated experimentally through measurement of sound pressure level and Brake Specific Fuel Consumption of engine. It showed those combination mufflers are more effective than reactive muffler even in small size. Shantanu V. Kanade et al [5] studied optimization of single chamber perforated muffler to calculate a transmission and insertion loss. Generic algorithm is used to optimize the various factors to achieve maximum transmission loss and insertion loss. Insertion loss has been found out for new and base model using mathematical implementation for different source impedance.

Zeynep Parlar et al [6] presented transmission loss of muffler using numerical approach as well as pressure acoustic approach. New designs were analyzed with respect to both acoustics and back pressure. New design of muffler shows maximum attenuation at minimum back pressure and it is validated using experimental investigation. S. P. Mogal et al [7] the focuses on control of generator noise using anti vibration mounts. Different sound absorbing materials are studied to minimize indoor noise level. Absorptive type of muffler is used to reduce noise level by $2 \mathrm{dBA}$. Various anti vibration mounts showed reduction in sound pressure level to 1-5 dBA. D. Tutunea et al [8] studied the reactive muffler using computation fluid dynamics (CFD). With this method the pressure, a velocity and temperature plot has been simulated for the muffler and and prediction of pressure loss has been carried for the muffler. New design shows good performance than original muffler. Vijay S. Jadhav et al [9] studied the noise attenuation and performance characteristics of the single cylinder diesel engine using different types of muffler. Three muffler are tested for the different loading conditions. Combined Reactive and Dissipative Muffler shows a good result in terms of sound pressure level, fuel consumption as compared to other mufflers. Middelberg et al [10] modeled simple expansion chamber muffler with different configurations and analyze by using CFD. Transmission loss of muffler has been found out and it is compared with published experimental results. Results showed good attenuation at the lower frequencies below approximately $1 \mathrm{kHz}$. For frequencies above $1 \mathrm{kHz}$ trend is followed closely. Orçun Saf et al [11] describe the characteristics of flow and acoustic properties of cross flow perforated mufflers. Paper investigates analytical, numerical and experimental methods to find out transmission loss. Geometrical design parameters and flow parameters are considered to investigate the acoustical and pressure performances on the perforated mufflers. Chandrashekhar bhat et al [12] studied the modal analysis to predict the transmission loss. Acoustic analysis has been carried out using finite element analysis method. Modal analysis is carried out for three different configurations of mufflers using different fixing conditions. It is noticed that three chamber muffler provides maximum attenuation at same conditions. M. Rahman et al [13] designed a new muffler for the stationary petrol engine. The performance characteristics and noise level of the muffler has been tested and compared with that existing muffler. The result has been found to be quite satisfactory. 


\section{CONCLUSION}

In this review paper the main emphasis has been given on study of the different types of muffler, muffler characteristics. The literature review suggests mathematical modeling and CFD approach can be used for calculating transmission loss. This review also discusses about selection criteria, design parameters and engine performance characteristics. This paper also emphasis on sound attenuation, back pressure which are most important criteria for selection of muffler. After reviewing procedures and methods for designing a muffler, we conclude that combination type of muffler is more efficient than reactive and absorptive mufflers. New theory for numerical analysis of muffler by 3D time domain CFD approach can be incorporated in designing muffler which is also preferable for new research work.

\section{REFERENCES}

[1] Ying-li Shao, Pei Wu, Ying-li Shao, 2010, “A Study on Exhaust Muffler with Low Backpressure”. IEEE, 2010, 978-1-4244-7739-5/10.

[2] Chen Liu, Zhenlin Ji, 2014, "Computational Fluid Dynamics - Based Numerical Analysis of Acoustic Attenuation and Flow Resistance Characteristics of Perforated Tube Silencers”, ASME Journal of Vibration and Acoustics, Vol.136, pp. 021006-1-11.

[3] Jun Chen, Xiong Shi, 2011, "CFD Numerical Simulation of Exhaust Muffler", Seventh International Conference on Computational Intelligence and Security, IEEE, 2010, 978-0-7695-4584-4/11 pp 1438-1441.

[4] S. Biswas, 2010, “Combination Muffler is more effective than Reactive Muffler even in Small Size”, IEEE, 978-1-4244-9082-0/10.

[5] Shantanu V. Kanade, A. P Bhattu, "Optimization of sound transmission loss and prediction of insertion loss of single chamber perforated plug muffler with straight duct”, AIJRSTEM, pp 14-308

[6] Zeynep Parlar, Sengül Ari, Rifat Yilmaz, Erdem Özdemir, and Arda Kahraman, 2013, “Acoustic and Flow Field Analysis of a Perforated Muffler”, World Academy of Science, Engineering and Technology Vol:7 2013-03-27 pp 600-604

[7] S. P. Mogal, Dr. R. K. Behera, S. Y. Pawar, 2011, "Design and Development of Muffler for Diesel Generator Set for Reduction of Noise”, International Journal of Engineering Science and Technology, Vol. 3, No. 4, pp. 3591-3595

[8] Dragos Tutunea, Madalina Calbureanu, Lungu Mihai, “Computational fluid dynamics analysis of a resistance muffler". Recent Advances in Fluid Mechanics and Heat \& Mass Transfer, pp 31-34

[9] Vijay S. Jadhav and Dhanaji M. Ghatage, 2010, “Noise Attenuation Of Diesel Engine With Different Types Mufflers”.

[10] Middelberg, J. M., Barber, T. J., Leong, S. S., Byrne, K. P., and Leonardi, E., 2004, "CFD Analysis of the Acoustic and Mean Flow Performance of Simple Expansion Chamber Mufflers”,ASME Paper No. IMECE2004-61371

[11] Orçun Saf, Bilen Egzost, Haluk Erol, 2010, “On Acoustics And Falow Behavior of the Perforated Mufflers”, ICSV17,pp1-8

[12] Chandrashekhar bhat, S.S.Sharma, Jagannath K, N S Mohan1, Sathisha S G, 2010, "Prediction of Sound Attenuation Characteristics of Mufflers”, World Journal of Engineering, volume 7,pp 115-16

[13] M. Rahman, T. Sharmin, A F M E. Hassan, and M. Al Nur 2005, "Design and construction of a muffler for engine exhaust noise reduction.” Proceedings of the International Conference on Mechanical Engineering, pp 1-6. 